\title{
O ESTÁGIO SUPERVISIONADO DA TEORIA À PRÁTICA: REFLEXÕES A RESPEITO DA EPISTEMOLOGIA DA PRÁTICA E ESTÁGIO COM PESQUISA, A LUZ DA PEDAGOGIA HISTÓRICO-CRÍTICA
}

\author{
Saulo Rodrigues de Carvalho ${ }^{1}$ \\ UNESP/UNICENTRO
}

\section{RESUMO}

Neste artigo realizamos uma reflexão a respeito da concepção de Estágio Supervisionado como Pesquisa. O estágio enquanto pesquisa que se fundamenta no campo teórico da epistemologia da prática, busca compreender metodologicamente o campo da prática de Estágio Supervisionado e aproximá-lo à pesquisa em educação constituindo-se em uma nova metodologia na formação do futuro pedagogo. Por meio da compreensão das particularidades da prática de estágio e das delimitações do campo da pesquisa e prática pedagógica, apresentamos uma crítica a respeito do pragmatismo presente nesta tendência teórica que se constrói para o estágio docente.

Palavras-chave: Estágio Supervisionado; Formação de Professores, Estágio com Pesquisa, Pedagogia Histórico-Crítica.

\section{THE TRAINEESHIP SUPERVISED FROM THEORY TO PRACTICE: REFLECTIONS ON THE EPISTEMOLOGY OF PRACTICE AND TRAINEESHIP DEVELOPMENT BY RESEARCH THE LIGHT OF THE HISTORICAL- CRITICAL PEDAGOGY}

\begin{abstract}
In this paper we will make one discussion about traineeship development by research. The traineeship while research that is based at theory of epistemological practical, quest, methodologically know the field of Traineeship Supervised and approximate it of the research in education constituting in a new methodological for education teachers future. Through comprehension of particularities of the practical and delimitations at field of research and pedagogy practical, we present one critical about pragmatism in the theoretical tendency that is building for the Internship Teachers.

Keywords: Traineeship Supervised, Teacher Training, Traineeship Development by Research, Historical-Critical Pedagogy
\end{abstract}

\section{Introdução}

Como professor da Universidade Federal do Amazonas (UFAM), tive o privilégio de orientar o Estágio Supervisionado no Município de Parintins. Como é de conhecimento a UFAM tem incorporado em suas diretrizes a concepção de Estágio Supervisionado com Pesquisa.

Um dos objetivos centrais do Estágio Curricular é ser um espaço de construção de aprendizagens significativas no processo de formação dos professores. Ou seja, junto com as disciplinas teóricas desenvolvidas nos cursos de formação, o estágio também, apresenta-se como responsável pela construção de conhecimentos que contribuem para o fazer 
profissional do futuro professor, ao possibilitar a efetiva articulação teoria-prática, por meio do contato com a realidade escolar (BRASIL, 2011, p.5)

Em Parintins-AM, o curso de Pedagogia do Instituto de Ciências Sociais, Educação e Zootecnia (ICSEZ), explicita esta relação entre Estágio e Pesquisa em seu Projeto Pedagógico de Curso (PPC).

O Estágio Supervisionado Profissional desenvolver-se-á com base no princípio da relação orgânica entre teoria e prática e será organizado e executado por área de formação a partir do $6^{\circ}$ período. As orientações serão realizadas no horário do curso, tomando por base o trabalho científico de acompanhamento [...] (PARINTINS, 2010, p.52 Grifos meus).

Durante dois semestres acompanhei as turmas que estagiaram no Ensino Infantil e nas séries iniciais do Ensino Fundamental e observei de perto tanto os êxitos, quanto as dificuldades que se apresentaram na execução da concepção de Estágio com Pesquisa, para a formação do Professor.

Dessa atuação resultou esta reflexão crítica que pretendo apresentar neste trabalho, de modo que se trata de uma análise das contradições que se apresentam no campo teórico dos fundamentos epistemológicos e práticos do Estagio Supervisionado com Pesquisa.

Adianto, porém, que não pretendo analisar aqui a situação particular do Estágio Supervisionado em Parintins, muito menos analisar as diretrizes e normas para a realização do Estágio Curricular da UFAM.

De outro modo, tal experiência na docência das disciplinas de estágio despertou-nos o interesse em realizar uma discussão teórica dos fundamentos epistemológicos do Estágio com pesquisa, por meio da Pedagogia Histórico-Crítica observando as categorias dialéticas da Singularidade, Particularidade e Universalidade, aplicadas ao Estágio.

A primeira parte deste trabalho é dedicada à reflexão da relação singular-particular da atividade de estágio, nela buscamos definir as particularidades do campo do estágio em educação, salientando sua relação aproximada com o cotidiano escolar. Destacamos ainda, os matizes teóricos do Estágio com Pesquisa, observando a Pedagogia das Competências e a teoria do Professor Reflexivo. Subsidiados pela crítica apresentada por Duarte (2003) ao caráter cético e pragmático da teoria de Donald Schön, levantamos questionamentos a respeito da reprodução do discurso pragmático neoliberal e da desvalorização da pesquisa científica no campo da educação, presente na concepção de Estágio com Pesquisa.

No item seguinte, direcionamos nossa argumentação a delimitar com mais precisão os campos da pesquisa e do estágio. Em Saviani (1980) ressaltamos a distinção dos níveis de investigação científica em educação, identificando as tendências da reflexão da prática, com o tipo de investigação aplicada e de desenvolvimento técnico. Ressalvando as afirmações de Moraes (2001), do imediatismo próprio das tendências da "prática reflexiva", nos reportamos aos estudos de Kopnin (1978) quanto ao conteúdo do reflexo do pensamento científico. Assim podemos chegar a compreensão do método de reflexão da prática como um tipo de "empirismo baconiano" (KHUN, 1975), um tipo de dedução presa ao limite do juízo do conceito científico (KOPNIN, 1978).

Por fim lançamos a discussão sobre o entendimento da Universalidade da prática docente enquanto prática social global. Para tanto, abrimos um debate imprescindível a respeito do trabalho docente, compreendendo suas determinações frente às categorias de Trabalho e Alienação fundamentando-nos na teoria de Marx (2002) e nos estudos da 
ontologia do ser social, apresentada por Lukács (2011). Por meio da perspectiva HistóricoCrítica (SAVIANI, 2000), (DUARTE, 2007), (GIARDINETTO, 1999), (MARTINS, 2007), reafirmamos a objetividade do conhecimento científico e a necessidade da sólida formação teórica para a compreensão da prática social global do professor, apontando o Estágio Supervisionado como um espaço para a maior compreensão das particularidades e universalidades do trabalho docente.

\section{Particularidades do Estágio Supervisionado em Educação}

O estágio é um momento em que os discentes das licenciaturas sentem aquela tensão e pressão típicas de testes de habilidades, como uma prova prática para tirar a habilitação de motorista, quando uma série de exercícios de como sair, parar, estacionar, balizar, são realizados para comprovar ou não a aptidão em dirigir. No estágio não é muito diferente. Isso acontece porque se criou um imaginário de que o estágio é o momento prático do curso. É no estágio que se separa os "fracos dos fortes", é aonde iremos realmente saber quem tem e quem não tem capacidade para ser professor. Assim como a prova de habilitação é o estágio que autorizará o discente a dirigir uma sala de aula.

No nosso exemplo da prova prática de habilitação, a mesma para se ter êxito, deve ser precedida de uma série de atos exaustivamente treinados, necessários para o cumprimento de certas formalidades exigidas pelo Estado e avaliadas minuciosamente pelo fiscal de prova. Muitos desses atos serão válidos somente para aquele instante de prova, quando então estiver com a habilitação em mãos e a licença para trafegar nas ruas, o motorista iniciante, começará realmente a aprender a conduzir, a dar características suas ao ato de dirigir.

Felizmente no estágio supervisionado as coisas não funcionam dessa maneira, ou pelo menos, não deveriam funcionar. Primeiro porque o estágio não é propriamente a parte "prática" do curso. É uma disciplina como outra, com fundamentos, ementário e objetivos. Ele não é a prática docente em-si, mas, um estudo que implica no exercício de uma pequena parte do complexo de relações que envolvem a prática escolar. Não são alguns meses de estágio e uma semana de regência que irão definir quem "tem vocação" e quem não "não tem vocação" para a docência, até porque compartilho da idéia de que não existem aptidões inatas, e que, portanto, asseguradas às condições de estudo e trabalho, todos são capazes de exercer o magistério.

Por outro lado, o estágio é um momento de observação mais próxima da prática real, mesmo que isso implique na tomada de ações tipicamente práticas, ele ainda se configura numa relação de (re)conhecimento da realidade. Contudo, ponderamos aqui, que numa perspectiva Histórico-Crítica, não é o observador que descobre a realidade, mas a realidade que se apresenta ao observador. Significa dizer que a prioridade do conhecimento está no objeto observado e que por mais instrumentalizada que seja a intervenção para conhecer a realidade, apenas uma parte desse real pode ser acessada (KOPNIN, 1978).

$\mathrm{Na}$ atividade de estágio essa relação permanece. A atividade de conhecimento do estagiário se dá na própria relação com o real, não numa relação unilateral aonde o discente vai até unidade escolar testar as teorias aprendidas na universidade, mas sim numa relação dialética, de compreensão das particularidades e contradições que envolvem o trabalho docente.

Seria mais fácil licenciar nossos alunos se o trabalho docente se resumisse ao "dar aulas", muito embora a atividade de ensinar predomine, existem outras atividades relacionadas ao cotidiano escolar que compõe o trabalho do professor, mostrando-se muitas vezes determinantes para a realização da sua atividade fim. Adentrar esse cotidiano, 
não é tarefa fácil. Também não é simples compreendê-lo utilizando-se apenas de esquemas teóricos. Ainda que necessários para essa tarefa tais modelos se mostram muito distantes da compreensão da particularidade da atividade escolar. É a partir deste ponto que analiso o Estágio Supervisionado, como uma chave que possibilita abrir a porta da relação escolar cotidiana.

Mas, notem que até o momento tenho trabalhado com uma categoria do conhecimento que é a particularidade, pretendo detalhar um pouco mais essa categoria daqui em diante, para depois retomar a sua concreção enquanto particularidade escolar, na qual o Estágio Supervisionado se insere como possibilidade de compreensão, o que nós vamos chamar de prática social global do trabalho docente (SAVIANI, 2000).

A categoria da particularidade se constitui no momento da mediação entre o conhecimento singular e o universal. Na concepção dialética "a compreensão dos fenômenos em sua processualidade e totalidade encontra respaldo apenas na dialética entre singularidade, particularidade e universalidade" (MARTINS, 2008, p.11), sendo que o particular delimita o campo das determinações que interferem na existência da singularidade e na concretização do universal. Vale dizer que o universal é sempre uma indeterminação (CHASIN, 1988) e que, portanto, pela mediação da particularidade no seu delineamento, a universalidade vai perdendo sua generalidade, deixando de ser uma grande abstração, para ganhar concretude.

Um ingressante em licenciatura que nunca lecionou anteriormente chega à universidade com uma dada visão sincrética do fenômeno educação, o qual, não é possível fazer conclusões mais aprofundadas sobre esse fenômeno social. Pela sua natureza teórica e sistêmica a universidade põe esse aluno em contato com o conhecimento histórico universal acumulado a respeito do fenômeno educativo. A apropriação do conhecimento universal por parte deste aluno, sempre será uma apropriação singular, pois "se refere às definibilidades exteriores irrepetíveis do fenômeno em sua relação imediata, acessível à contemplação viva, ou seja, refere-se a sua identidade" (PASQUALINI, 2010). Neste patamar, Universalidade e Singularidade se relacionam ainda de forma abstrata. As mediações onde singularidade e universalidade do fenômeno educativo se encontram estão nas particularidades do conhecimento. No campo da educação a escola, ou melhor, as práticas escolares, em certas circunstâncias ${ }^{2}$, tornam-se uma das particularidades do conhecimento do pedagogo. Particularidade essa que delineia o universal. O conhecimento universal agora se faz o universal da prática escolar. Ao delimitar o universal este se torna a particularidade de uma dada singularidade, em nosso caso a singularidade do professor.

O campo do estágio possui a especificidade em explorar uma esfera particular do conhecimento do pedagogo. É, portanto, um processo de conhecimento da prática escolar, delimitado pela prática escolar. Mesmo a prática escolar não é acessada em sua totalidade, por ser a prática de determinada sala de aula em determinada escola. Não quero dizer com isso que a totalidade do conhecimento da prática escolar se torna inacessível, mas, de outro modo, pretendo elucidar a constituição de um novo particular-universal. Neste sentido a prática escolar pode ser encarada como um “complexo de complexos”, cuja determinação mais simplificada, ou seja, sua Universalidade encontra-se no ato de transmitir e reproduzir nos indivíduos, de maneira sistematizada, o conhecimento historicamente acumulado (SAVIANI, 2000).

Ao dizer isso gostaria neste instante de abrir um diálogo com as tendências que defendem o campo de estágio como lugar da pesquisa do pedagogo. As concepções do professor reflexivo compreendem que a prática docente deve ser acompanhada de uma reflexão do seu fazer e do seu ser (ALARCÃO, 2011). Neste sentido é compreensível sua defesa por uma formação superior que possibilite aos futuros professores uma análise 
constante da sua prática, a partir de um modelo lógico-gnosiológico que já virou bordão, o da "ação-reflexão-ação".

Partindo do exame da natureza da atividade de estágio, podemos compreender que este se constitui de uma particularidade do trabalho do professor, uma parte da ação pedagógica, que não corresponde à sua totalidade. Vale dizer, portanto, que a atividade de pesquisa relacionada a esta particularidade é muito bem vinda, mas não pode, de modo algum, limitar os horizontes do campo educativo, da ação do professor, a unicamente examinar a sua prática escolar. A pedagogia é uma ciência, uma forma superior de conhecimento da educação, isto implica conhecimento e desenvolvimento das esferas filosóficas, sociológicas, éticas, artísticas, didáticas e práticas da educação, permanecer num único campo seria um erro.

Nesse sentido alerto para os perigos de uma formação que se especialize na prática e não dê o devido trato para outros campos fundamentais no desenvolvimento e compreensão do ato educativo.

Outro problema que enxergo no estreitamento da pesquisa em educação voltado para a reflexão da prática do professor está no acionamento de tendências extremamente pragmáticas da educação. No risco iminente do olhar específico da prática cotidiana do professor provocar um ocultamento de outras variantes que influenciam a educação. De outro modo, tal movimento reflete o momento atual da política educacional vigente, onde o Estado Mínimo retira investimentos dos setores sociais dando prosseguimento a uma política de privatização da esfera pública. No âmbito da educação as políticas de Estado têm transferido a responsabilidade da qualidade do ensino unicamente para a figura do professor, por meio de mecanismos de avaliação e controle que tendem a perpetuar um sistema de baixos investimentos na educação. Uma formação voltada para a análise da prática do professor, pode invariavelmente legitimar uma política que deposita o problema da educação unicamente nas debilidades da prática docente, deixando de fora as determinantes políticas, econômicas que interferem no andamento da educação pública.

Para entender essa relação precisamos adentrar um pouco mais nas alterações, as quais, a reestruturação produtiva e a política neoliberal submeteram, em especial, à educação estatal ${ }^{3}$. O Estado Mínimo trouxe grandes problemas para o dimensionamento da força de trabalho na nova política do capitalismo em todas as esferas da produção e também no âmbito do funcionalismo público, principalmente nos serviços que cabem no atendimento à população. Numa análise grosseira da configuração da produção e da política econômica, temos por um lado um altíssimo investimento no campo das Ciências e Tecnologia, com intuito exclusivo de aumentar a produtividade e de outro lado temos uma diminuição do uso da força de trabalho, acompanhado de arrochos salariais, perdas de direitos e revisão do preço da força de trabalho sempre em baixa. Também as exigências da formação da força de trabalho tornaram-se cada vez mais genéricas e menos erudizadas. Uma formação generalista, mas a ponto de só observar aquilo que está relacionado ao seu trabalho.

Nestas últimas décadas temos assistido o avanço de várias técnicas laborais fundadas principalmente no toyotismo. Tal ideologia do trabalho destaca-se por frisar que mais importante para o bem estar dos trabalhadores é viver pela empresa e melhorar sempre a sua produtividade ${ }^{4}$. No entanto, esse discurso esconde uma crise no centro da produção capitalista que não consegue mais incorporar a grande massa da força de trabalho à produção. Com o mercado de trabalho em crise, outros mecanismos de exclusão do trabalhador são ativados, estes não mais se fundamentam no grau de escolaridade e quantidade de diplomas e certificados acumulados durante a vida. Conjunturalmente ainda que necessários os diplomas e certificados para a disputa do emprego perdem relevância, o 
que baliza agora a escolha do empregador se fundamenta na avaliação de competências $e$ habilidades, que se encontram na "capacidade de mobilizar diversos recursos cognitivos para enfrentar um tipo de situações" (PERRENOUD, 2000, p.15).

Deste modo, como reflexo da crise levantou-se no seu entorno um leque de teorias que muito embora busquem uma explicação para o fenômeno do desemprego, se perdem em discursos legitimadores. As pedagogias das competências se incluem nesse campo, por serem na verdade formas de persuasão dos indivíduos a se adaptarem ao funcionamento do modo de produção em crise. Ainda segundo Perrenoud (2000) esta é uma pedagogia voltada para possibilitar a adaptação dos sujeitos às situações do cotidiano. Assim, numa situação de crise de emprego são as competências e habilidades que permitirão que os trabalhadores mantenham seus postos de trabalho adaptando-se as mudanças do sistema. A prática surge como um elemento fundamental para esse tipo de avaliação, da "práticapara-a-prática", tendo o conhecimento tácito e não o científico como seu alicerce.

Dessa forma, o conhecimento tácito, ou saber intuitivo, se coloca como nova perspectiva de padrão para o alcance de um emprego mantendo distante a crise das forças produtivas do capital, assentando unicamente sobre os indivíduos a responsabilidade pelo sucesso ou fracasso do seu trabalho. Uma ideologia perversa, pois concede sempre ao empregador a palavra final da avaliação da competência ou não competência para o trabalho. (CARVALHO 2010, p.61)

O conhecimento tácito não só fundamenta a teoria de Perrenoud (2000), como também alicerça as teorias do profissional reflexivo. Podemos ver em Duarte (2003) que o conhecimento tácito está aliado a um processo de desvalorização do conhecimento científico, pois estaria centrado no "saber fazer" cotidiano, destinando a um plano secundário o saber elaborado e sistematizado das ciências.

Como se pode ver, Schön defende que a escola deve deslocar seu foco de atenção do conhecimento escolar para o conhecimento tácito (cotidiano), deve deixar de considerar o saber escolar superior ao saber cotidiano e deve valorizar as formas de percepção e pensamento próprias da prática cotidiana. Esse tipo de educação escolar é que deveria, segundo Schön, constituir o fundamento da formação do professor reflexivo. É por esta razão que o saber escolar (o saber acadêmico, teórico, científico) também deveria deixar de ser o fundamento dos cursos de formação de professores. (DUARTE, 2003, p. 620)

Ao tecer uma crítica rigorosa a Donald Schön, Duarte (2003) identifica uma forte influência do universo ideológico pós-moderno e do neoliberalismo à epistemologia da prática. Diz:

A disseminação, no Brasil, dos estudos na linha da "epistemologia da prática" e do "professor reflexivo", na década de 1990, foi impulsionada pela forte difusão da epistemologia pós-moderna e do pragmatismo neoliberal, com os quais a epistemologia da prática guarda inequívocas relações. (DUARTE, 2003, p. 610)

O caráter cético e pragmático da epistemologia da prática estaria em acordo com algumas das afirmações neoliberais da "infinitude do real", da impossibilidade da concretude do conhecimento, defendido por Hayek, um dos "papas" do neoliberalismo 
(DUARTE, 2003). É possível ver também a confirmação na tese de Duarte em outro texto de Hayek (2009), onde o mesmo defende a maior importância do conhecimento "desorganizado", não-científico, sobre o conhecimento científico, para a sociedade:

Conhecer e saber operar uma máquina que não estava sendo adequadamente explorada, ou a habilidade de alguém que poderia ser mais bem aproveitada, ou estar consciente de um excedente de reservas que pode ser usado durante uma interrupção temporária do fornecimento, é tão útil socialmente quanto o conhecimento das melhores técnicas alternativas. (HAYEK, 2009)

O critério de utilidade do conhecimento que aparece no exemplo de Hayek é também um dos sustentáculos do pragmatismo de John Dewey, filósofo com o qual Donald Schön nunca escondeu ter sido influenciado. Neste sentido deixo alguns questionamentos em relação à aplicação única e exclusiva do campo de estágio para o campo da pesquisa docente, até onde o hermeneutismo da pesquisa da prática do professor, reproduz o discurso utilitarista presente no neoliberalismo? Até que ponto a adoção inconteste dos referenciais da epistemologia da prática na aplicação do Estágio tem propiciado a desvalorização do conhecimento científico na formação do Pedagogo? E por fim, como superar as formas tradicionais de avaliação do Estágio Supervisionado sem cair no praticismo das tendências contemporâneas de educação?

\section{Para pensar a orientação do Estágio Supervisionado: delimitando os campos da pesquisa e do estágio.}

Quando estive à frente da disciplina de Estágio Supervisionado pude compreender que a orientação do estágio ultrapassa o auxílio à construção de especializados planos de ensino (ainda que necessários ao bom planejamento), ou de aulas regência que se transformem em grandes espetáculos (sem negar que toda aula deva ser preparada explorando o máximo de suas potencialidades). Penso, que essa orientação deva se aproximar da etimologia da palavra "Paidéia", isto é, a formação de uma cultura escolar. Orientar o estágio nesta perspectiva significa um processo aonde o mais experiente conduz o menos experiente a alcançar um nível de conhecimento mais próximo do seu nível de conhecimento. De maneira mais ampla inserir o futuro professor no vasto campo da pedagogia, permitindo-lhe transitar por entre o conhecimento científico e prático de sua atuação. Implica, no entanto, compreender as especificidades de cada campo do saber.

Para a pesquisa em educação concordamos que existe a necessidade de investigar a prática docente que visa o desenvolvimento de novas técnicas e metodologias de ensino. Contudo, a atividade de pesquisa não se limita ao descobrimento técnico-científico. Como salientou Saviani (1980) sobre o esquema de Juif e Dovero ${ }^{6}$ a respeito das distinções dadas à pesquisa em educação, a prática educacional e a prática social global relacionam-se "reciprocamente num processo em que as partes não podem ser compreendidas isoladamente e sem a referência do todo, da mesma forma que o todo não pode ser compreendido senão nas suas relações com as partes que o constituem" (SAVIANI, 1980, p.86). Nesse texto Saviani alertava para os problemas da predileção de pesquisas pedagógicas do tipo de "Investigação Fundamental", ou seja, a pesquisa de ponta, a "investigação pura dos cientistas" (Id.) destinada ao conhecimento de novos campos de investigação. Hoje temos um momento inverso, onde a investigação aplicada e de 
desenvolvimento técnico, propalam uma aludida autonomia frente à prática social global e ao tipo de Investigação Fundamental. Vivemos um momento da pesquisa em educação em que a investigação das partes tem determinado unilateralmente a Investigação Fundamental, de modo pragmático. Por conseguinte o pragmatismo das tendências "práticas" em educação tem promovido um profundo "recuo da teoria" no campo pedagógico, como observa Moraes (2001):

A celebração do "fim da teoria" - movimento que prioriza a eficiência e a construção de um terreno consensual que toma por base a experiência imediata ou o conceito corrente de "prática reflexiva" - se faz acompanhar da promessa de uma utopia educacional alimentada por um indigesto pragmatismo (Burgos, 1999, p. 68) em tal utopia praticista basta o "saber fazer" e a teoria é considerada perda de tempo ou especulação metafísica e quando não, restrita a uma oratória persuasiva e fragmentária presa à sua própria estrutura discursiva. (MORAES, 2001, p. 10)

Para entender este processo precisamos ir mais à fundo no que entendemos por Ciência e por Pesquisa. Longe de matizar uma idéia metafísica sobre o conhecimento científico, devemos situá-lo primeiro no seu contexto histórico. A ciência como produto da atividade humana derivada da relação material entre o homem e a natureza, se apresenta dessa forma determinada pelas necessidades materiais do homem em cada momento histórico.

O método científico é historicamente determinado e só pode ser compreendido dessa forma. O método é o reflexo das nossas necessidades e possibilidades materiais, ao mesmo tempo em que nelas interfere. Os métodos científicos transformam-se no decorrer da História. No entanto, num dado momento histórico, podem existir diferentes interesses e necessidades; em tais momentos, coexistem também diferentes concepções de homem, de natureza e de conhecimento, portanto, diferentes métodos. Assim, as diferenças metodológicas ocorrem não apenas temporalmente, mas também num mesmo momento e numa mesma sociedade. (ANDERY e outros, 1988 p. 17, grifo meu)

Ao tomar o conceito de reflexo, podemos situar a ciência no âmbito da necessidade histórica de conhecer e interpretar de maneira objetiva o mundo. Antes de tudo, diz Kopnin (1978), a ciência é "um sistema de conhecimento humano com objeto determinado e método conhecido" (p.20). Mas, até aqui os argumentos da "prática reflexiva" parecem coadunar com nossa concepção de Ciência. Nesse momento é preciso descortiná-los.

Como salienta Moraes (2001) a reflexão da teoria da "prática reflexiva" está presa ao empírico, encontrando nele seus limites e possibilidades. Dessa observação, podemos acrescentar ainda que, a ciência tornou-se uma atividade complexa ${ }^{7}$, que se desprende numa autonomia relativa à prática e mais ainda à qualquer empirismo.

Dado que a prática desempenha certa função no movimento do conhecimento, servindo-lhe sobre tudo de critério de verdade, só neste sentido estreito, podemos considerá-la um elo do conhecimento. Mas, por si mesma a prática não é atividade teórica e reduzi-la ao conhecimento implicaria em cometer um erro crasso, em substituir a atividade material prática pelo pensamento teórico (KOPNIN, 1978, p.171) 
A reflexão sobre a prática não pode ser considerada em si, como uma ciência, assim como o pensamento teórico não pode substituir a prática pedagógica. A proposta de "reflexão-na-ação", da prática como pesquisa, esquece-se de um princípio fundamental para o desenvolvimento de qualquer pesquisa ou nova teoria, que "[...] por mais particular que seja seu âmbito de aplicação, nunca ou quase nunca é um mero incremento ao que já é conhecido. Sua assimilação requer a reconstrução da teoria precedente e a reavaliação dos fatos anteriores" (KUHN, 1975, p. 26 grifo meu).

Kuhn (1975) faz uma alusão ao empirismo baconiano, que apesar de utilizar experimentos, apresentava uma série de problemas que o impedem de ser qualificado como ciência, "[...] hesita-se em chamar de ciência a literatura resultante" ou as "histórias baconianas" (KUHN, 1975, p.36).

$\mathrm{Na}$ esteira da experiência baconiana, encontramos na abordagem reflexiva, ou epistemologia da prática, um modelo de pesquisa alinhavado com o método experimental desenvolvido por Francis Bacon. Alarcão (2011) é quem nos explica esse modelo que compreende quatro fases, a) experiência concreta, b) observação reflexiva, $c$ ) conceptualização e d) experimentação ativa. Afirma:

A essência do modelo é muito simples. Por processos de observação e reflexão, a experiência é analisada e conceptualizada. Os conceitos que resultam desse processo de transformação servem, por sua vez, de guias para novas experiências, o que confere à aprendizagem um caráter cíclico, desenvolvimentista. (ALARCÃO, 2011, p. 53)

O problema do a-historicismo identificado por Kuhn (1975) no método experimental de Bacon, a sua pseudo-cientificidade, parecem estar presentes também na pesquisa experimental reflexiva. Os conceitos que resultam da experiência são descritos por Alarcão de maneira informe, como se surgissem apenas da observação, deixando de lado o fato de que os conceitos são preenchidos por conteúdos que se formam por um longo processo de conhecimento, "[...] o resumo de determinada etapa do conhecimento, anteriormente adquirido" (KOPNIN, 1978, p. 203). O caráter pseudo-científico deste modelo, encontra-se na impossibilidade de ultrapassar o juízo sobre determinado conhecimento. Kopnin (1978) observa que "o desenvolvimento do juízo leva à dedução que não subentende, mas fundamenta a conexão entre o singular e o universal. A dedução atua como unidade entre o conceito e o juízo" (p.190). Contudo o juízo pode tanto refletir a realidade adequadamente, quanto deturpá-la, já que o mesmo "[...] é toda idéia relativamente acabada, que reflete as coisas, os fenômenos do mundo material, as propriedades, conexões e relações destes" (p.198)

Ainda que integrante do processo do conhecer científico e fundamental para a formação dos conceitos, o juízo não consegue ultrapassar a esfera da aparência dos fenômenos. O conceito por outro lado, "reflete o conteúdo que as coisas encerram" (KOPNIN, 1978, p.204), é o reflexo das leis e do movimento do real. É fulcral a compreensão de que os conceitos científicos surgem necessariamente da atividade prática do homem, contudo a epistemologia da prática compreende a atividade prática do ser humano como um dado singular circunscrito na sua realidade empírica, não como uma prática histórico-social. Essa inflexão do pensamento da prática-reflexiva sobre o conhecimento científico não compreende o "movimento" e a "flexibilidade dos conceitos", ou melhor, interpreta-os de maneira deturpada como demonstra Kopnin (1978) ao elucidar a metafísica atual: 
Se antes a metafísica trivial achava que os objetos e conceitos não mudam em essência, já a metafísica atual (sofística) reconhece o movimento dos conceitos, mas o separa da fonte objetiva do movimento do mundo material. O movimento dos conceitos é visto em si mesmo fora da relação com o movimento dos objetos. Neste caso o movimento dos conceitos se converte em arbítrio do sujeito, vale dizer, vulgariza-se, perde sua importância fim (p. 211).

Se observarmos mais de perto a proposta que se funda na prática reflexiva do professor, a relação entre o movimento dos conceitos e o movimento dos objetos se efetiva de maneira fraturada, uma vez que a natureza dos conceitos é estabelecida de forma arbitrária pelo sujeito do conhecimento, ou seja, pelo professor pesquisador-reflexivo ${ }^{8}$. Nesse caso a concepção de sujeito consubstancia-se na consciência individual isolada, isto é, o conceito surge da prática, não da prática histórico-social, mas da prática empíricoindividual dos sujeitos, que a sistematizam e a conceituam.

$\mathrm{Na}$ concepção dialética a consciência individual isolada não pode ser separada do processo de investigação, mas expressa, a consciência universal do sujeito coletivo do conhecimento. Nesse prisma o sujeito do conhecimento é compreendido como uma "individualidade singular concreta" significa que esse sujeito pode conhecer a totalidade do objeto e "deve conhecer a totalidade do objeto, ainda mais, conhecer é só conhecer quando a totalidade do objeto é compreendida. Só é objetivo o conhecimento da totalidade. O conhecimento só é concreto quando referido ao todo" (CHASIN, p.2, 1988).

Nesse sentido concordamos com Kopnin (1978) quando salienta a impossibilidade de se criar um novo método investigativo capaz de ensinar as pessoas a fazerem conhecimentos científicos por meio da lógica e dedução rigorosas, como pretendem fazer as tendências do Professor Reflexivo e Professor Pesquisador. Vejamos o que diz Kopnin (1978):

Todos sabem, porém que o descobrimento científico é um fenômeno bastante raro, que não só não é feito por todas as pessoas, mas nem de longe por todos os que lidam com ciência. Em princípio é impossível um sistema lógico rigorosamente formalizado de processo que leve a descobrimentos na ciência, porque cada descobrimento é bastante complexo por sua estrutura lógica e reúne traços estritamente individuais, que não se repetem. (p.223)

Não existe uma fórmula para fazer descobrimentos científicos, embora existam métodos científicos que permitam a aproximação com a objetividade do conhecimento, não há uma "lógica" que garanta descobrimentos científicos. Lógica e dedução são elementos fundamentais para a pesquisa, mas dialeticamente superados 9 . Isto significa também que é impossível fazer ciência sem a lógica, mas que incorporada ao pensamento dialético, a compreensão da totalidade do objeto de pesquisa, possibilita o conhecimento concreto do objeto.

O motivo pelo qual chamo a atenção para esta característica da lógica baseia-se no fato de que as tendências pedagógicas que se fundamentam na "epistemologia da prática" de matiz shöniana são enfáticas em afirmar que a reflexão da prática realizada adequadamente leva a aquisição de novos conhecimentos e resolução de problemas. Ao elucidar a experiência dessa tendência no Brasil a educadora portuguesa Isabel Alarcão, realça o caráter investigativo e formativo da prática reflexiva para o professor afirmando a sua efetividade no descobrimento de conhecimentos ligados a prática docente. 
Continuo a acreditar nas potencialidades que nos oferece a proposta do professor reflexivo. No meu país reconheço nela um potencial que tem ajudado os professores a tomarem consciência da sua identidade profissional que, só ela, pode levar a permanente descoberta de formas de desempenho de qualidade superior e ao desenvolvimento da competência profissional na sua dimensão holística, interativa e ecológica. (ALARCÃO, 2011, p. 46 grifo meu)

Imbuídos no espírito do "saber fazer" profissionais, e apoiados sobre os princípios metodológicos da pesquisa-ação, os defensores da epistemologia da prática, compreendem que essa concepção científica deva ser instituída cada vez mais cedo na formação do professor endossando o Estágio Supervisionado como momento mais apropriado e possível de se realizar a pesquisa educacional. Como salientam Ghedin e Almeida (2008):

[...] a partir dos princípios da pesquisa-ação-crítico-colaborativa, é possibilitar ao professor em formação inicial compreender que o conhecimento é elaborado na prática a partir das teorias educacionais que possibilitam a reelaboração das próprias teorias, que sustentam as práticas educativas. Essa dialética permite-nos desenhar um quadro teórico imbricado com a prática formativa, de tal modo que não há como separar os processos de investigação dos procedimentos da aprendizagem da profissão na experiência do estágio. (p. 16)

A orientação do estágio nessa perspectiva aponta para um reordenamento do campo de estágio capacitado a unificar a teoria e a prática historicamente cindidas no âmbito da formação de professores. O estreitamento desse campo passa obrigatoriamente pela concepção prático-reflexiva do trabalho docente, onde a teoria se fecha no objeto da pesquisa e a prática se funda na resolução de um determinado problema de pesquisa. Tal proposição como salientamos apenas aparentemente realiza a junção teoria e prática, quando na realidade provoca um afastamento da teoria, uma vez que é a teoria para a resolução de um determinado problema em subsunção pela prática.

\section{Fundamentos para a discussão da prática social global como ponto de partida para a reflexão do trabalho docente.}

Até aqui ponderamos sobre a especificidade e o desenvolvimento do conhecimento científico. Agora pretenderemos especificar a natureza da prática docente, para compreender de qual prática emerge de fato a teoria.

Muito se deve ao marxismo pela compreensão das práticas humanas e em específico da atividade prática fundamental para a sociabilidade, o trabalho. Conforme Marx (2002) o homem pode ser diferenciado dos outros animais por vários atributos, mas é no trabalho, na sua capacidade de produzir meios de subsistência e meios de produção sob um constante processo qualitativo de transformação da natureza, que ele se faz humano, que ele se constitui enquanto gênero.

O marco ontológico da atividade humana é o trabalho e é por meio do trabalho que se fundam as demais práticas sociais, é a atividade vital a "condição natural eterna da vida humana" (MARX, 2002, p.218). O trabalho em si é uma atividade que implica uma determinada reflexão sobre a realidade. Constitui-se, no entanto na unidade entre o pensamento previamente idealizado e o resultado de uma prática objetivada, uma atividade 
destinada a um fim conhecido. Marx (2002) categoricamente ressalta essa característica do trabalho ao comparar o pior arquiteto com a melhor abelha:

[...] o que distingue, essencialmente, o pior arquiteto da melhor abelha é que ele construiu a célula na sua cabeça antes de fazê-la em cera. No fim do processo de trabalho aparece um resultado que já estava presente desde o início na mente do trabalhador que, deste modo, já existia idealmente. Ele não efetua apenas uma mudança de forma no elemento natural; ele imprime no elemento natural, ao mesmo tempo, seu próprio fim, claramente conhecido, o qual constitui a lei determinante do seu modo de agir e ao qual tem de subordinar a sua vontade. (MARX, 2002, p. 212)

Marx nos credencia a dizer que não há trabalho sem reflexão. Por mais simples e banal que seja o trabalho a ser realizado, sua objetivação exige certa reflexão sobre a atividade prática a ser realizada das propriedades e legalidades do objeto a ser transformado (ainda que se fundamente na mera observação da natureza). O entendimento da centralidade do trabalho na constituição do ser social nos é dado aprofundadamente por Lukács (2007) observando-o como "modelo de toda práxis social” (p.4) e diz:

É claro, como veremos mais adiante, que não se deve ser esquemático e exagerar este caráter paradigmático do trabalho em relação ao agir humano em sociedade; mas assim mesmo, ressalvadas as diferenças, que são muito importantes, veremos que há uma essencial afinidade ontológica e esta brota do fato de que o trabalho pode servir de modelo para compreender as outras posições sócio-teleológicas exatamente porque, quanto ao ser, ele é a forma originária. (p.4)

Com isso Lukács quer nos dizer que para além do trabalho existem outras práticas sociais diferentes e relativamente independentes dele, mas que para serem compreendidas na sua essencialidade, dependem do discernimento ontológico do complexo social edificado pelo trabalho. Quer dizer também, que todo trabalho se realiza pela prática, mas que nem toda prática pode ser considerada trabalho. Se observarmos a prática do professor veremos uma prática social com objetivos e fins definidos, uma práxis, que tem em ultima instância como produto a aula. Para a realização do seu trabalho é imprescindível a reflexão do que irá ser ensinado. A reflexão, no entanto, nem sempre expressa um nível aprofundado de objetividade, criticidade e concretude da realidade. Uma aula, repetitiva, livresca ou "mal dada" não deixa de ser uma prática refletida. Isso de fato não elimina o caráter reflexivo da prática docente, mas coloca para o professor a tarefa de elaborar a reflexão sobre a sua atividade prática. Entendendo que toda prática social tem como fundamento a protoforma do trabalho (LUKÁCS, 2007), de uma atividade teleológica, é possível afirmar que não existe prática social irrefletida, a questão a se por não é se o professor reflete ou não reflete a sua prática, mas o conteúdo dessa reflexão.

O que determina então o conteúdo da reflexão do professor? Para essa resposta não nos basta entender somente as singularidades e particularidades da prática docente, ou o ser e o fazer do professor, mas entender a suas características universais, enquanto sujeito da práxis pertencente a uma determinada classe social. Esse corte classista, no entanto, visto pelas tendências pós-modernas como ultrapassado e finado é a chave para a compreensão do conteúdo refletido pela prática docente. Quanto a isso, nos cabe dizer brevemente, que tal questão passa ao largo da "catequese" reflexiva da epistemologia da 
prática. Embora haja uma crítica interna que vise a maior discussão dos problemas políticos e ideológicos presentes na prática do professor, os mesmos são apresentados num enfoque individualista, no qual a capacidade crítica e a competência prática dos indivíduos singulares a partir da sua reflexão sobre a prática lhes possibilitarão a sensibilização e o combate às injustiças sociais postas na sociedade e presentes na escola. Conquanto necessários à capacitação e o compromisso individual se tornam insuficientes para o enfrentamento das desigualdades sociais, geradas no âmago da sociedade classes, a oposição a esses fenômenos da sociedade capitalista, necessita de um posicionamento de classe, de um conhecimento mais específico do seu movimento político e ideológico.

A primeira característica universal fundamental para a compreensão da prática docente é de que o professor é um trabalhador assalariado. Isso significa que para sua reprodução individual ele precisa vender sua força de trabalho por um determinado período de tempo em troca de um salário. A condição de assalariamento não só coloca-o forçosamente em contradição com as classes dirigentes da sociedade (a burguesia e seus auxiliares), mas como também o coloca em contradição com sua atividade prática ${ }^{10}$. Como trabalhador o professor também é inserido na reprodução social do capitalismo nas condições de alienação do seu trabalho. $\mathrm{O}$ fato de vender sua força de trabalho para $\mathrm{o}$ Estado ou para um capitalista, não anula o pressuposto da divisão social do trabalho que o constrange a realizar sua atividade em correspondência aos seus meios de vida. O caráter intelectual da prática do professor não elimina o "poder social" que atua sobre seu ser. Conscientemente ou não ele realiza sua práxis em uma estrutura social que tem como finalidade a reprodução e a manutenção de um sistema de exploração que também o oprime. Quando adentra ao sistema de ensino, independente de gosto, vocação ou necessidades individuais, é premido por currículos, leis, projetos, a ensinar aquilo que é hegemônico na formação social que está inserido, aquilo que é socialmente útil. A respeito desse aspecto universal impresso pela divisão do trabalho Marx e Engels (1965) assinalam:

O poder social, ou seja, a força produtiva multiplicada, que nasce da cooperação de vários indivíduos condicionados pela divisão do trabalho, não se apresenta a esses indivíduos como sua força própria, fruto da união, porque tal cooperação mesma não é voluntária, mas natural. Ela lhes aparece, ao contrário, uma força estranha situada fora deles, de cuja origem e fim nada sabem, que não podem mais dominar e que, ao contrário, passa por uma sequencia particular de fases e estágios de desenvolvimento tão independente da vontade e da marcha da humanidade que na verdade dirige essa vontade e essa marcha. (p.31).

O fenômeno da Alienação é tão presente na prática do trabalhador manual, quanto na prática do trabalhador intelectual. É evidente que há distinções nas suas manifestações, que correspondem às particularidades de suas atividades, mas considerando a extensão e as controvérsias postas sobre essa questão e os limites desse artigo, não faremos essa discussão neste momento. Contudo, as definibilidades do trabalho docente não decorrem de uma decisão consciente do professor, é tão somente produto de circunstâncias historicamente determinadas de processos sócio-políticos contraditórios, os quais o professor se relaciona de maneira alienada.

A alienação é uma forma de ser do capital, que enquanto sociometabolismo tende a transformar todas as relações humanas em relações entre mercadorias. Por ser uma determinação sócio-histórica não se escolhe ser ou não alienado, os indivíduos se inserem socialmente sob essa condição no capitalismo, que acarreta em problemas tanto de ordem sociológicos quanto psicológicos, como nos mostra Martins (2007). 
Portanto, na medida em que a alienação é característica inerente à organização social capitalista, o problema da consciência dos indivíduos sobre ela revela-se como um problema de grau, que será maior ou menor dependendo do quanto o indivíduo possa compreender sua existência para além da particularidade, ou seja, possa superar sua condição particular em direção a condição humano-genérica. (p. 137)

Ao investigar a formação social da personalidade do professor, Martins (2007) aborda os efeitos negativos da alienação sobre sua consciência e o desenvolvimento de sua prática. Acertadamente aponta para o processo de apropriação das objetivações genéricas como possibilidade de compreensão e resistência as estruturas desumanizadoras e alienantes da sociedade.

[...] é socialmente fundamentado na consciência sobre a natureza inacabada, histórica, dos homens que os educadores podem implementar transformações efetivamente humanizadoras em outros indivíduos, transformando-se a si mesmo neste processo. Assim sendo a superação da contradição referida encontra-se na dependência do grau de alienação a que se encontra subjugado o educador, que tanto será maior ou menor quanto puder apropriar-se das objetivações genéricas para-si e estabelecer relações entre sentidos e as significações dos seus atos, posto o papel fundamental que tais condições desempenham na produção da consciência. (MARTINS, 2007, p.149)

Martins nos chama a atenção para a ação preponderante do conhecimento como potencial de transformação efetivamente humanizadora na sociedade. Porém, não é todo e qualquer conhecimento que carrega consigo esse potencial, senão, o conhecimento das objetivações genéricas para-si que são formas superiores de conhecimento da realidade, como a estética, as ciências, a matemática, a filosofia, a arte. "São formas que impelem a uma apropriação sistemática e intencional, constitutiva de uma natureza 'intelectual' do conhecimento" (CARVALHO, 2012, p.20). Em outras palavras, para ensinar o professor precisa aprender o que foi historicamente produzido pelo gênero humano, deve se apropriar das objetivações genéricas para-si nesse processo, para transformar as consciências de outros indivíduos, transformando a si mesmo.

De fato o que Martins (2007) salienta é uma reflexão sobre a prática, mas um debruçar sobre a prática histórico-social dos homens. Ao refletir sobre a práxis humana na sua constituição histórico genérica, o professor compreende a si e a sua própria atividade enquanto prática social historicamente determinada e determinante.

Isso nos leva a compreender que, a alienação seria, portanto um fator decisivo na elaboração do conteúdo da reflexão do professor sobre o seu trabalho. $\mathrm{O}$ grau de alienação demarca o alcance de sua compreensão e ação sobre a realidade. Entretanto, no ato de conhecer e de se apropriar da produção humano genérica, o professor se coloca de frente à universalidade do conhecimento definindo dessa forma o conteúdo da sua reflexão. Neste ponto concordamos com Saviani (2000), Duarte (2007), Giardinetto (1999), Martins (2007), que existe um conhecimento objetivo da realidade e que suas formas mais elevadas devem ser transmitidas pela escola, portanto, ao reconhecer tal objetividade e universalidade do conhecimento o professor passa a compreender que seu trabalho é parte de uma totalidade social pensando sua prática a partir de um entendimento concreto de sua ação. 
Mas a teoria do professor reflexivo concebe o conhecimento como uma construção individual, por esse motivo volta sua reflexão para a sua experiência prática e para a investigação do conhecimento tácito como já foi mencionado por nós. Embora seja admitida certa "cultura objetiva", as ações e soluções que os profissionais encontram frente aos problemas que surgem da sua ação prática, a teoria serviria, portanto como articuladora entre os saberes dos professores e da prática institucional (PIMENTA e LIMA, 2008).

O papel da teoria é oferecer aos professores perspectivas de análise para compreender os contextos históricos, sociais culturais, organizacionais e de si mesmos como profissionais, nos quais se dá sua atividade docente para neles intervir, transformando-os. Daí, é fundamental o permanente exercício da crítica às condições materiais na quais o ensino ocorre. (p.49)

Aparentemente Pimenta e Lima (2008) defendem uma sólida formação teórica para amparar as reflexões dos professores sobre sua atividade. No entanto, se observarmos mais atentamente, o papel da teoria de que nos falam as autoras, se resume no alargamento das perspectivas interpretativas do professor, uma vez que o conhecimento é um constructo individual. Coerente com os pressupostos da epistemologia da prática, de que não é possível chegar a uma objetividade do conhecimento, mas sim em interpretações dele, a teoria neste caso daria suporte para o professor realizar a sua própria construção do conhecimento da realidade. Ressaltam ainda a necessidade constante da crítica as condições materiais de ensino, um ponto no qual as autoras em certo momento do livro identificam como uma questão frágil na proposta do Professor Reflexivo.

Mas como fazer a crítica se a realidade não passa de interpretações dos indivíduos? Como é possível realizar a crítica sem dominar os conteúdos culturais e políticos para fazer valer seus interesses? A desconsideração da objetividade do conhecimento faz com que essa questão passe despercebida pela teoria do professor reflexivo, que procura, por parte de alguns de seus adeptos superar esses limites admitindo uma "cultura objetiva", buscando dessa forma, introduzir questões de natureza política na reflexão do professor. Pimenta e Lima (2008) tentam resolver esse problema da teoria, adjetivando ao termo professor reflexivo a expressão professor intelectual crítico e reflexivo. Contudo, coesas com a proposta original ${ }^{12}$ direcionam a criticidade do professor para o interior da sua atividade prática, isto é, o questionamento das condições materiais para o exercício da docência e afirmam:

A análise contextualizada do conceito de professor reflexivo permite superar suas limitações, afirmando-o como um conceito políticoepistemológico que requer o suporte de políticas públicas consequentes para sua efetivação. Caso contrário, se transforma em mero discurso ambíguo, falacioso e retórico, servindo apenas para se criar um discurso que culpabiliza os professores. Discurso que ignora ou mesmo descarta a análise do conjunto de suas teorias e principalmente, dos contextos nos quais foram produzidas e para os quais eventualmente, têm sido férteis no sentido de potencializar a efetivação de uma democracia social com mais igualdade, para o que contribui a democratização quantitativa $e$ qualitativa dos sistemas escolares. (PIMENTA e LIMA, 2008 p.54 grifo meu) 
A crítica do agora professor intelectual crítico reflexivo se encerra no questionamento da instituição escolar, das relações políticas constituídas no seu interior, dos campos teórico-metodológicos existentes e na perspectiva de melhoramento das condições para a realização do trabalho docente.

Mesmo admitindo alguma objetividade do conhecimento para o exercício da reflexão crítica, as teorias do professor reflexivo e professor intelectual crítico reflexivo tendem a permanecer na superficialidade da crítica social, não reconhecendo o caráter classista da sociedade que perpassa o âmbito escolar e delimita o como, quando e o quê deve ser ensinado.

Estamos convencidos dessa forma de que a reflexão do professor sobre sua prática implica no entendimento das forças sociais que balizam a natureza e as especificidades dessa prática, marcadas profundamente por antinomias interpostas pela sociedade dividida em classes antagônicas.

Como Saviani (2008) compreendemos que a educação "[...] não transforma de modo direto e imediato e sim de modo indireto e mediato, isto é, agindo sobre os sujeitos da prática" (p.58), para isso é fundamental o processo de "instrumentalização", de disponibilizar o conteúdo histórico social do conhecimento acumulado pela humanidade, na compreensão da "prática social global" e sua efetiva transformação.

O engajamento do professor na sua prática consiste neste sentido, na superação da divisão do saber. A reflexão sobre sua prática passa a motivar a busca do saber objetivo colocando-o a serviço dos interesses da classe dominada, inclui "dominar o que os dominantes dominam" (SAVIANI, 2000).

\section{Conclusão}

Podemos apresentar neste exposto uma ponderação crítica da concepção de Estágio como Pesquisa e da epistemologia da prática. A partir da compreensão da Particularidade e Universalidade do trabalho docente, nos foi possível traçar um panorama dos equívocos, aos quais estão suscetíveis a formação do profissional reflexivo no estreitamento da pesquisa e da prática pedagógica ao campo do Estágio Supervisionado.

No momento em que a prática pedagógica se fecha no estágio como campo da investigação científica, promove-se uma verdadeira restrição da pesquisa em educação projetando esta ciência, para o campo da investigação aplicada e do desenvolvimento técnico das práticas educacionais, que muitas vezes não conseguem ultrapassar o juízo de determinado conhecimento (KOPNIN, 1978), vertendo-se numa simplificada aproximação grosseira entre prática e teoria. Deste modo, a reflexão sobre a prática, quando realizada sob a ponto de vista fenomênico empirista, tende a compactuar com o pragmatismo presente na produção capitalista, legitimando em diversos pontos, os seus desdobramentos políticos e ideológicos.

Da mesma maneira, buscamos demonstrar que não existe trabalho docente irrefletido e que, portanto, o cerne da discussão da formação docente encontra-se no conteúdo da reflexão docente. $\mathrm{Na}$ sociedade capitalista a alienação infundida pela divisão de classes e a instituição do trabalho assalariado, determinam em larga medida o conteúdo da reflexão do professor. É neste sentido que amparados na leitura Histórico-Crítica sobre trabalho docente, defendemos a orientação do Estágio Supervisionado, bem como a formação do futuro docente, alicerçado num sólido conhecimento da prática social global do professor, compreendendo tanto suas características histórico-universais quanto suas particularidades e singularidades. 
Para finalizar, destacamos que a prática transformadora do professor tem sua efetividade na transformação das consciências, "agindo sobre os sujeitos da prática" como salienta Saviani (2008), e que para isso, a reflexão sobre a sua prática invariavelmente se alinha à reflexão sobre o conhecimento objetivo acumulado pela humanidade, colocando-o a serviço das classes dominadas.

\section{Referências}

ALARCÃO, I. Professores reflexivos em uma escola reflexiva. $8^{\text {a }}$ ed. São Paulo, 2011.

ANDERY, M. A. Para compreender a ciência: uma perspectiva histórica. Rio de Janeiro: EDUC, 1988.

BRASIL. Diretrizes para os estágios supervisionados nos cursos de licenciaturas da Universidade Federal do Amazonas. UNIVERSIDADE FEDERAL DO AMAZONAS. Pró-Reitoria de Ensino de Graduação-PROEG, Manaus, 2011.

CARVALHO, S. R. Políticas neoliberais e educação pós-moderna no ensino paulista. Dissertação de Mestrado. Universidade Estadual Paulista, 2010.

CARVALHO, S. R. Marxismo, educação e formação da individualidade: o caminho das objetivações genéricas em-si às objetivações genéricas para-si. Caderno Sala de Aula. Manaus: EDUA, Ano 1, V. 1, p. 11-28, jan/jun, 2012.

COSTA, G. M. Serviço Social em debate: ser social, trabalho, ideologia. Universidade Federal de Pernambuco (UFP). Dissertação de Mestrado, (texto revisado para publicação), 2009

DUARTE, N. Conhecimento tácito e conhecimento escolar na formação do professor (por que Donald Schön não entendeu Luria). Educação e Sociedade. Campinas, V.24, n. 83, p. 601-625, agosto 2003.

DUARTE, N. Educação escolar, teoria do cotidiano e a escola de Vigotski. $4^{\text {a }}$ ed. Campinas: Autores Associados, 2007. (Coleção Polêmicas do nosso tempo)

CHASIN, J. Método Dialético. Aulas ministradas durante o curso de pós-graduação em Filosofia Política. Universidade Federal de Alagoas - UFAL, 1988. Transcrição Literal. Disponível em: <http://orientacaomarxista.blogspot.com.br/2010/10/metodo-dialetico-josechasin.html> Acesso em: novembro de 2010.

GHEDIN, E. e ALMEIDA, W. A. Fundamentos epistemológicos do desenvolvimento do estágio com pesquisa. Poiésis Pedagógica. v. 5/6 p. 15-32, jan-dez, 2008.

GIARDINETTO, J.R.B. Matemática Escolar e Matemática da Vida Cotidiana. Campinas: Autores Associados, 1999.

HAYEK, F. A. O uso do conhecimento na sociedade. Disponível em: <http://www.ordemlivre.org/node/356> acesso em: 3 jan 2009.

JAEGER, W. Paidéia: a formação do homem grego. São Paulo: Martins Fontes, 1995.

KOPNIN, P. V. A dialética como lógica e teoria do conhecimento. Rio de Janeiro: Civilização Brasileira, 1978.

KUHN, T. S. A estrutura das revoluções científicas. São Paulo: Perspectiva, 1975. 
LUCKÁCS, G. Introdução a uma estética marxista. Rio de Janeiro: Civilização Brasileira, 1970.

LUKÁCS, G. Ontologia do ser social: o trabalho. Tradução provisória de Ivo Tonet. Versão digital enviada por<ivo_tonet@yahoo.com.br> em 16 de maio de 2007.

MARTINS, L. M. A formação social da personalidade do professor: um enfoque vigotskiano. Campinas: Autores Associados, 2007. (Coleção formação de professores)

MARTINS, L. M. As aparências enganam: divergências entre o Materialismo Histórico Dialético e as abordagens qualitativas de pesquisa. In: 29a Reunião Anual ANPED Filosofia da Educação/GT7/. Disponível em: <http://www.anped.org.br/reunioes/29ra/trabalhos/trabalho/GT17-2042--Int.pdf.> Acesso em: Agosto de 2008.

MARX, K. O Capital: o processo de produção do capital. Livro1. Volume I. 27. ed. Rio de Janeiro: Civilização Brasileira, 2002.

MARX, K. \& ENGELS, F. A ideologia alemã e outros escritos. Rio de Janeiro: Zahar, 1965.

MORAES, M. C. M. O recuo da teoria: dilemas da pesquisa em educação. Revista Portuguesa de Educação, v.14, n.001, p.7-25, 2001.

PASQUALINI, J. C. Dialeticidade singular-particular-universal. Mimeo, 2010

PARINTINS. Instituto de Ciências Sociais Educação e Zootecnia. Projeto Pedagógico do Curso de Pedagogia. Universidade Federal do Amazonas, Parintins, 2010.

PERRENOUD, P. Dez novas competências para ensinar. Porto Alegre: Artes Médicas Sul, 2000.

PIMENTA, S. G e LIMA, M. S. L. Estágio e docência. 3ª ed. São Paulo: Cortez, 2008. (Coleção docência em formação)

SAVIANI, D. O problema da pesquisa na pós-graduação em educação. In: Educação: do senso comum à consciência filosófica. São Paulo: Cortez/Autores Associados, 1980.

SAVIANI, D. Escola e Democracia. ed. comemorativa. Campinas: Autores Associados, 2008.

SAVIANI, D. Pedagogia Histórico-Crítica: primeiras aproximações. Campinas: Autores Associados, 2000.

SCHÖN, Donald. Educando o profissional reflexivo: um novo design para o ensino e a aprendizagem. Porto Alegre: Artes Médicas, 2000.

Notas

${ }^{1}$ Doutorando e Mestre em Educação Escolar pelo Programa de Pós-Graduação em Educação Escolar da
Faculdade de Ciências e Letras (FCL) da Universidade Estadual Paulista (UNESP). Professor Colaborador do
curso de Pedagogia da Universidade Estadual do Centro Oeste do Paraná (UNICENTRO). Membro do Grupo
de Pesquisa em Trabalho, Educação e História - GETEH/CNPq.
${ }^{2}$ Dizemos isso porque essa não é uma relação unívoca, há momentos em que, singular, particular e universal
mudam de posição, aonde um se transforma no outro (LUKÁCS, 1970). Numa aula de didática, por exemplo,
a prática escolar poderia ser considerada o universal dessa relação, uma vez que são abstraídas as
determinações concretas para analisá-la.

Revista HISTEDBR On-line, Campinas, $n^{\circ}$ 52, p. 321-339, set2013 - ISSN: 1676-2584 
${ }^{3}$ Ver: CARVALHO, S.R. Políticas neoliberais e educação pós-moderna no ensino paulista. Dissertação de Mestrado. Universidade Estadual Paulista, 2010.

${ }^{4} \mathrm{O}$ kaizen que significa "mudança para o melhor" é apresentado pelas empresas como uma filosofia laboral que juntamente com as técnicas dos Cinco "S" visa melhorar a relação dos empregados com o seu próprio trabalho.

${ }^{5}$ Paidéia segundo Jaeger (1995) era a palavra que designava a função do escravo (pedagogo) que conduzia o amo aos estudos. Mais tarde essa palavra passou a significar para os gregos o ideal de formação do homem, e tinha um significado análogo ao que foi denominado posteriormente por cultura, “... foi sob a forma de Paidéia, de 'cultura', que os gregos consideraram a totalidade de sua obra criadora em relação aos outros povos da Antiguidade que foram herdeiros" (JAEGER, 1995 p.7)

${ }^{6}$ Juif e Dovero distinguem três níveis de investigação pedagógica, a Investigação Fundamental, a Investigação Aplicada e a Investigação de desenvolvimento técnico. "O segundo nível sugere uma aplicação direta dos resultados da pesquisa fundamental na prática pedagógica; trata-se, pois, de uma prática cientificamente controlada (a analogia do engenheiro é a propósito bem expressiva). O terceiro nível, em contrapartida, sugere uma aplicação indireta dos resultados da pesquisa fundamental; trata-se de uma atividade paralela, uma espécie de fábrica destinada a produzir os aparelhos e equipamentos em geral, necessários ao incremento da prática pedagógica" (SAVIANI, 1980, p. 85)

${ }^{7}$ Aqui nos desvencilhamos de qualquer teoria da complexidade de matiz pós-moderna. Para nós o entendimento de complexo, se dá porque no seu entorno se desenvolveram outras práticas e métodos que embora se diferenciem quanto as suas formas e finalidades, são também reconhecidos pelo campo da ciência, pois se desenvolvem sobre uma mesma base material.

${ }^{8}$ Ghedin e Almeida (2008), principalmente, têm trabalhado na perspectiva de aproximar as teses da teoria do professor reflexivo com a teoria do professor pesquisador, para fundamentar uma teoria do estágio enquanto pesquisa.

${ }^{9}$ Superação como categoria da dialética implica em afirmar que a lógica formal do pensamento torna-se parte integral da lógica concreta do pensamento dialético, "Com efeito a lógica dialética não é outra coisa senão o processo de construção do concreto de pensamento (ela é uma lógica concreta) ao passo que a lógica formal é o processo de construção da forma de pensamento (ela é, assim, uma lógica abstrata). Por aí, pode-se compreender o que significa dizer que a lógica dialética supera por inclusão/incorporação a lógica formal (incorporação, isto quer dizer que a lógica formal já não é tal e sim parte integrante da lógica dialética)". (SAVIANI, 1980, p.9, grifo meu)

${ }^{10}$ A atividade do professor é iminentemente intelectual, como atividade intelectual sua finalidade, "o 'material' da posição do fim é o homem, suas relações, suas ideias, seus sentimentos, suas vontades, suas aptidões" (LUKÁCS, apud COSTA, 2009, p.80), não cabe colocar a ela qualquer determinação produtivista. Deste modo sua prática social real entra em contradição com os imperativos produtivistas do capital, inserindo o trabalho docente no espectro da competitividade, eficiência e qualidade total, como se educar uma pessoa fosse equivalente a montar um carro.

${ }^{11}$ Fiz questão de reproduzir o termo usado por Pimenta e Lima (2008) conservando as aspas, pois me chamou a atenção a maneira como foi escrito essa expressão no seu texto, o que nos dá duas interpretações possíveis, a de que o termo a ser utilizado não é o mais adequado para representar tal situação, ou a de que a autora não se responsabiliza pela expressão, pois pertenceria a outra pessoa, ou corrente de pensamento que não o seu.

${ }^{12}$ Cabe lembrar que a proposta original da teoria do professor reflexivo apresentada por Schön (2000) não trás a dimensão política como uma preocupação fundamental para a reflexão dos professores.

Recebido em dezembro-2012

Aprovado em outubro-2013 